\title{
Akıllı Telefonlarda Yapı Analizi için Hızlı Yakınsayan Moment Dağıtma Algoritması
}

\author{
Önder Halis BETTEMIR ${ }^{1}$
}

ÖZ

Yapım süreci boyunca iş iskelesi ve geçici yapılar üzerinde tasarım aşamasında öngörülemeyen yükleme birleşimleri oluşabilir. Saha mühendisleri inşaat aşamasında çabuk karar almaları gerektiği için güvensiz sonuçlara sebep olabilecek sezgisel kararlar alabilmektedir. $\mathrm{Bu}$ çalışmada saha mühendislerine yardımcı olmak amacıyla elde taşınabilen cihazlarda çalışabilen moment dağıtma tabanlı yapı analiz algoritması önerilmiş̧ir. Geleneksel moment dağıtma yöntemi tek analizde yanal deplasman ve oturmaya maruz yapıları çözebilecek şekilde iyileştirilmiştir. Bu sayede önerilen algoritma sınırlı hafıza ve işlem gücüne sahip elde taşınan cihazlarda verimli biçimde çalıştırılabilmektedir. Bu sayede saha mühendisleri yapım aşamalarını sahada gerçek zamanlı analiz edip doğru kararları anında alabileceklerdir.

Anahtar Kelimeler: Moment dağıtma yöntemi, açı yöntemi, inşaatta bilgi teknolojileri, karar destek sistemi.

\section{ABSTRACT \\ Fast Converging Moment Distribution Algorithm for Structural Analysis on Smartphones}

Throughout the construction, unforeseen loading combinations on the scaffolding and the temporary facilities may occur. Since the site engineers have to take quick decisions, they make intuitive decisions, which may cause failures. In this study, moment distribution method based structural algorithm, which can run on handheld devices, is proposed to assist site engineers. Conventional moment distribution method is improved to solve the frames that are free to sidesway and settlement at once. As a result, the proposed algorithm can be efficiently implemented on hand-held devices, which have limited memory and processing power. Whereby, the site engineer can analyze any construction phase real-time and immediately take sound decisions.

Keywords: Moment distribution method, slope-deflection, IT in construction, decision support system

Not: Bu yaz1

- $\quad$ Yayın Kurulu'na 13.04.2015 günü ulaşmıştır.

- 31 Mart 2017 gününe kadar tartışmaya açıktır.

1 İnönü Üniversitesi, İnşaat Mühendisliği Bölümü, Malatya - onder.bettemir@inonu.edu.tr Carnegie Mellon Üni., İnşaat ve Çevre Müh. Bölümü, PA, ABD - bettemir@andrew.cmu.edu 


\section{GİRiş}

Tasarım aşamasında genellikle bitmiş yapı ve yapım aşamasının bazı önemli kilometre taşları analiz edilmektedir. Ancak, yapım sırasında öngörülemeyen birçok durum oluşmaktadır. İş iskelesi ve kalıplara önceden analiz edilmemiş ve tehlike arz edebilen yüklemelerin etki etmesi olasıdır. İnşaatın daha kısa sürede bitirilebilmesini sağlamak için birden fazla iş kalemi aynı anda yürütülür. Yapının değişik katlarında aynı anda duvar örülmesi, sıva ve dış cephe uygulamalarının yürütülmesi nedeniyle iş iskeleleri birden fazla ekip tarafından aynı anda kullanılır.

Şantiye uygulamaları ile ilgili durumların çözümünden saha mühendisleri sorumludur. Ancak, hiperstatik sistemlerin çözümünü gerektiren durumlarda çözüme el hesabı ile ulaşılamaz. Bunun sonucunda yapı analiz programı ile sistemin çözülmesi gerekmektedir. Yapı analiz programları genellikle şantiye için tahsis edilmez ve tasarım bürolarında bulunur. Buna ilaveten, şantiyede yapı analiz yazılımının bulunması halinde dahi saha mühendisinin inşaatı durdurup şantiye ofisinde şüpheli durumu analiz etmesi gereği ortaya çıkmaktadır. Sonuç olarak durumun analiz edilerek karar alınması inşaatın gecikmesi ile sonuçlanmaktadır. Bu nedenle özellikle inşaat projesinin süre bakımından kritik olduğu durumlarda analizden kaçınarak saha mühendisleri deneyimlerine dayanarak sezgisel kararlar almaktadır. Sezgisel kararların alınmasını engellemek için yükleme koşullarını anında analiz edebilecek ve elde taşınabilir cihazlarda çalışabilen yapı analiz yazılımına ihtiyaç duyulmaktadır.

$\mathrm{Bu}$ çalışmada akıllı telefonlarda ve programlanabilir hesap makinelerinde çalışabilen Moment Dağıtma Yöntemi (MDY) tabanlı bir yapı analiz algoritması geliştirilmiştir. MDY'nin mevcut durumu yanal deplasman yapabilen ve oturma gözlenen yapıların çözümü için matris tersi hesabını gerektirmektedir. MDY iyileştirilerek matris tersi hesaplanmasına gerek kalmadan yapıların analiz edilebilmesi sağlanmıştır. Geliştirilen algoritma Android Studio yazılımı kullanılarak kodlanmış ve Android 2,2 ve daha ileri sürümdeki Android işletim sistemine sahip akıllı telefonlarda çalışabilir yazılım geliştirilmiştir. Analizlerin şantiyede gerçek zamanlı yapılması merkez ofisle iletişim gereksinimini önemli ölçüde azaltacak ve yapım sürecinin daha güvenli ve hızlı ilerlemesini sağlayacaktır.

\section{2. İYILEŞTIRILILMIŞ MOMENT DAĞITMA YÖNTEMI}

Moment dağıtma yöntemi, açı yöntemi ile elde edilen denklemlerin Jacobi tekrarlı çözüm yöntemi ile çözümüne dayanır [1,2]. Moment dağıtma yöntemi çok açıklıklı kirişler ve çerçeve yapılarda kesin çözüme çok yakın sonuçlar sunmaktadır [3]. Ancak, yanal deplasman ve farklı oturmaların olduğu yapıların çözümü için MDY'nin birden fazla sayıda uygulanması gerekmektedir. MDY'nin uygulama alanını genişletmek için eleman rotasyonları ve düğüm noktası rotasyonları birlikte ifade edilerek yanal deplasman ve oturmaya maruz yapıların tek analizle çözümü mümkün kılınmıştır. Birden fazla analiz gerekliliği ortadan kaldırılarak matris tersi hesaplanması zorunluluğu giderilmiştir. Eleman rotasyonları ve düğüm noktalarının aynı anda çözümü MDY'de çözüm sistemine dahil olmayan yanal deplasman ve oturma değişkenlerinin çözüm sistemine dahil olmasına neden olmuştur. $\mathrm{Bu}$ parametrelerin yakınsama üzerindeki etkileri ve yakınsama hızı detaylı biçimde incelenmiştir. Şekil 1 de yer alan sistemin açı yöntemi ile çözümü için oluşturulan denklem kümesinde $\theta_{B}, \theta_{C}, \Delta$, ve $\delta$ olmak üzere 4 adet bilinmeyen bulunmaktadır. Yanal 
deplasmanı ifade eden parametre, $\Delta$, pozitif $x$ doğrultusunda, oturmayı ifade eden parametre, $\delta$, pozitif y doğrultusunda ölçülmektedir [1-4]. Açı denklemleri yinelemeli Gauss-Siedel yöntemi ile çözülebilir biçime uyarlanarak denklem kümesi 1 elde edilir.

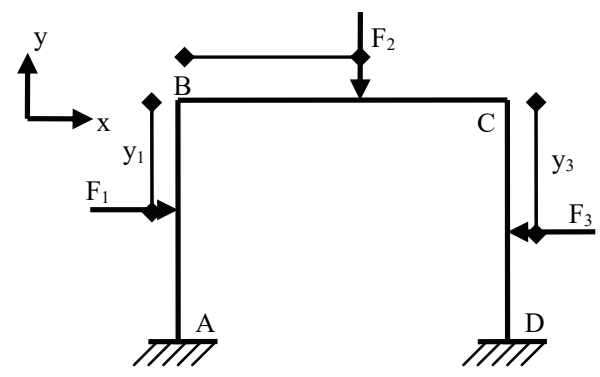

Sekil 1. Yanal deplasman ve oturmaya maruz tek katl çerçeve yapı

$\partial \theta_{B}^{i+1}=-\frac{\partial \theta_{C}^{i} 2 E K_{B C}-\frac{\partial \Delta^{i} 6 E K_{A B}}{l_{A B}}+\frac{\partial \delta^{i} 6 E K_{B C}}{l_{B C}}}{\left\{4 E K_{A B}+4 E K_{B C}\right\}}$

$\partial \theta_{C}^{i+1}=-\frac{\partial \theta_{B}^{i+1} 2 E K_{B C}-\frac{\partial \Delta^{i} 6 E K_{C D}}{l_{C D}}+\frac{\partial \delta^{i} 6 E K_{B C}}{l_{B C}}}{\left\{4 E K_{B C}+4 E K_{C D}\right\}}$

$\partial \Delta^{i+1}=\frac{l_{A B}^{2} l_{C D}^{2}}{12 E\left(K_{A B} l_{A B}^{2}+K_{C D} l_{C D}^{2}\right)}\left[\frac{6 E K_{A B} \partial \theta_{B}^{i}}{l_{A B}}+\frac{6 E K_{C D} \partial \theta_{C}^{i}}{l_{C D}}\right]$

$\partial \delta^{i+1}=-\frac{6 E K_{B C}\left\{\partial \theta_{B}^{i}+\partial \theta_{C}^{i}\right\}}{\frac{12 E K_{B C}}{l_{B C}}+k l_{B C}}$

Başlangıç durumu için genel olarak çerçeve sisteminin düğ̈̈m noktalarındaki açılar sıfır kabul edilir. Bu durumda $\partial \Delta$ ve $\partial \delta$ terimlerinin başlangıç değeri denklem 2'ye eşit olur.

$$
\begin{aligned}
& \partial \Delta^{0}=\frac{l_{A B}^{2} l_{C D}^{2}\left[+\Sigma F_{X}+\Sigma F \cdot E \cdot M+\frac{M_{1}}{l_{A B}}+\frac{M_{3}}{l_{C D}}\right]}{12 E\left(K_{A B} l_{A B}^{2}+K_{C D} l_{C D}^{2}\right)} \\
& \partial \delta^{0}=-\frac{F \cdot E \cdot M_{B C}+F \cdot E \cdot M_{C B}+M_{2}}{\frac{12 E K_{B C}}{l_{B C}}+k l_{B C}}
\end{aligned}
$$


Denklem 1.a ve 1.b düğüm noktalarındaki açıyı, 1.c yanal deplasman değişimi, 1.d ise oturma miktarlarını güncellemektedir. Denklem 2'de belirtilen ifadeler MDY'den daha karmaşık görünse de her iki yöntem aynı karmaşıklığga sahiptir. Parametrelerin ilk değerlerinin atanmasından sonra ankastre momentleri ve her elemana tekabül eden dönme momentleri moment dağıtma tablosunun ilgili hücresine yazılır. Moment dağıtma işlemine uygun bir düğüm noktasının serbest bırakılması ile başlanır. Bir düğüm noktası serbest bırakıldığında dengeleyici moment eklenerek moment dengesi sağlanır. Dengeleyici moment $k E K \theta_{j}^{i}$ ifadesine eşit olmalıdır. Burada $\theta_{j}^{i}$, $i^{\prime}$ ninci tekrarda $j$ düğüm noktasının dönme miktarını, $k E K$ ise düğüm noktasının dönmeye olan direncini belirtmektedir. Tüm düğüm noktaları serbest bırakıldığında $\partial E K \Delta^{i+1}$ ve $\partial E K \delta^{i+1}$ terimleri düğüm noktaları için hesaplanan düzeltmeler eşitlik 1.c ve $1 . \mathrm{d}$ de yerlerine konarak bulunur. $\Delta$ ve $\delta$ terimleri hesaplandığında eşitlik 1 de yer alan ifadelerdeki katsayılarla çarpılarak eleman rotasyon momentleri hesaplanır. Eleman uç momentlerinin hesaplanması ile ilk yenileme tamamlanmış olur. Eleman rotasyon momentlerinin eklenmesi yatay ve düşey yöndeki kesme kuvvet eşitliğini sağlarken düğüm noktalarındaki denge denklemlerinde tutarsızlığa yol açar. Bu nedenle düğüm noktaları tekrar serbest bırakılarak düğüm noktalarındaki moment dengesi sağlanır. Ancak bu sefer kesme kuvveti eşitliği denklemleri tutarsız duruma gelir. Her yinelemede tutarsızlıkların mutlak değeri küçülür ve tekrarlar moment değerlerine getirilen düzeltme büyüklükleri önceden tayin edilen eşik değerinden daha küçük hale gelene kadar sürdürülür.

\subsection{Yanal deplasmana maruz oturma olmayan basit çerçeve yapı}

İyileştirilmiş moment dağıtma yöntemi Şekil 1'de gösterilen tek katlı çerçeve yapıda $\mathrm{AB}=\mathrm{CD}=3 \mathrm{~m}, \mathrm{BC}=4$ metre, $\mathrm{I}_{\mathrm{AB}}=\mathrm{I}_{\mathrm{CD}}=\mathrm{I}$ ve $\mathrm{I}_{\mathrm{BC}}=4 \mathrm{I}, \mathrm{F}_{1}=30 \mathrm{kN}, \mathrm{y}_{1}=1 \mathrm{~m}, \mathrm{~F}_{2}=40 \mathrm{kN}$, $\mathrm{x}_{2}=2 \mathrm{~m}, \mathrm{~F}_{3}=0 \mathrm{ve}, k_{A}=k_{D}=\infty$, için incelenmiştir. $\mathrm{AB}$ ve $\mathrm{CD}$ kolonlarının sertliği $\mathrm{K}$ ve $\mathrm{BC}$ kirişinin sertliği $3 \mathrm{~K}$ olarak belirlenmiştir.

Denge denklemleri

B Düğüm noktası

$\mathrm{M}_{\mathrm{BA}}+\mathrm{M}_{\mathrm{BC}}=0, \quad 16 \mathrm{EK} \theta_{\mathrm{B}}+6 \mathrm{EK} \theta_{\mathrm{C}}-2 \mathrm{EK} \Delta-6,667=0$

$$
E K \theta_{B}^{i+1}=\frac{-6 E K \theta_{C}^{i}+2 E K \Delta^{i}+(6,667)}{16}
$$

C Düğüm noktası

$\mathrm{M}_{\mathrm{CB}}+\mathrm{M}_{\mathrm{CD}}=0, \quad 6 \mathrm{EK} \theta_{\mathrm{B}}+16 \mathrm{EK} \theta_{\mathrm{C}}-2 \mathrm{EK} \Delta+20=0$

$$
E K \theta_{C}^{i+1}=\frac{-6 E K \theta_{B}^{i}+2 E K \Delta^{i}+(20)}{16}
$$

$A B$ ve $C D$ Kolonları

$$
\mathrm{H}_{\mathrm{A}}+\mathrm{H}_{\mathrm{D}}=\sum \mathrm{Fx} \quad E K \Delta^{i+1}=0.75 E K \theta_{B}^{i}+0.75 E K \theta_{C}^{i}+(8,333)
$$


16EK, B düğüm noktasının dönmeye direnci (Denklem 3.a)

16EK, C düğüm noktasının dönmeye direnci (Denklem 3.b)

$0,75 \mathrm{EK} \theta_{B}^{i}+0,75 \mathrm{EK} \theta_{C}^{i}$, yanal deplasman (Denklem 3.c)

-2EK $\Delta^{\mathrm{i}}$, yanal deplasman ile AB kolonundaki momentler (Denklem 3.a)

-2EK $\Delta^{\mathrm{i}}$, yanal deplasman ile CD kolonundaki moment Denklem 3.b de belirtilmiştir

\subsection{Yanal deplasman ve oturmaya maruz çerçeve}

D düğüm noktasındaki temel pabucunun yay katsayısı 5/3EI N/m değeri atanıp diğer parametreler aynı tutularak çerçeve yapı tekrar çözülmüştür. D dügüum noktasındaki oturma nedeniyle BC kirişi dönecek ve kirişin eleman uçlarında rotasyon momenti oluşacaktır. Oturma miktarı bilinmediği için rotasyon açısı ve rotasyon momenti bilinmeyecektir. Çerçeve yapı MDY ile analiz edilecek olsaydı Şekil 2'de ifade edildiği gibi 3 kere MDY'nin uygulanması gerekecekti. Fakat yapılan iyileştirme ile yanal deplasman, oturma ve dügüum noktalarının dönmesi beraber çözülebildiği için tek seferde yapının çözülebilmesi mümkün kılınmıştır. Dokuzuncu yinelemenin sonunda en büyük düzeltme başlangıç değerinin $\% 0,0008$ 'inden daha küçük duruma gelmiştir.

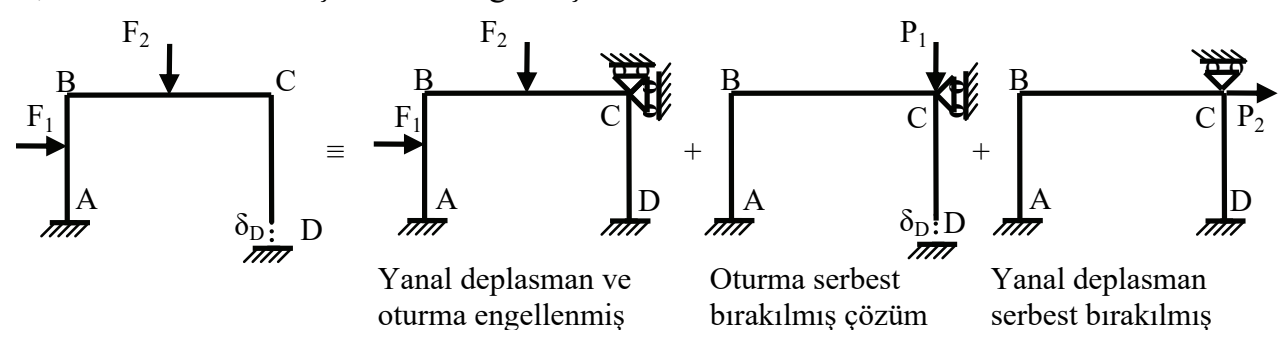

Şekil 2. Yanal deplasman ve oturma görülen çerçevenin çözümü

\subsection{Oturmanın olmadığı çok katlı çerçeve yapı}

Çok katlı yapılarda yöntemin davranışını incelemek için iki katlı iki açıklıklı yapı analiz edilmiştir. Yapıdaki 9 düğüm noktasından 6'sı serbest, diğer 3'ü ise sabittir. Eleman rotasyonlarının ayrı incelenmesi durumunda moment dağıtma işleminin üç kere uygulanması gerekmektedir. Analiz 10 tekrardan sonra durdurulmuş ve yatay kuvvetlerdeki uyuşmazlık birinci kat için \%0,013 ikinci kat için \%0,082 olarak hesaplanmıştır. Eleman uç momentlerinin esas değerlerinden en büyük sapması $0,08 \mathrm{kNm}$ olarak hesaplanmıştır. Yakınsama için 54 kere dengeleyici moment dağıtılmış ve 18 kere rotasyon momenti eklenmiştir ve 400 çarpma yapılmıştır. Yedinci tekrardan sonra eleman uç momentlerinde kayda değer bir ilerleme olmamıştır. Yüksek hassasiyette çözüme ihtiyaç duyulmayan durumlarda analiz, hesap yükünü azaltmak için daha erken durdurulabilir.

Çok katlı yapı, orta aksta yer alan temel pabucunun yay katsayısı $k_{H}=25 / 6$ EI alınarak tekrar çözülmüştür. Bu yapının MDY ile çözümü için 4 defa MDY'nin uygulanması gerekmektedir. Buna ek olarak elde edilen denklem kümesinin çözümü 3x3 boyutundaki 
matris tersinin alınmasını gerektirmektedir. İyileştirilen MDY ile yapılan 10 tekrardan sonra yatay kuvvetlerin uyumsuzluğu birinci kat için \%0,013 ikinci kat için \%0,083 olarak hesaplanmıştır. Oturma nedeniyle yakınsama ihmal edilebilir düzeyde yavaşlamıştır.

Beşinci örnek problemde bir iş iskelesi analiz edilmiştir. 7 katlı, 5 açıklıklı iş iskelesi üzerinde 48 düğüm noktası, 77 eleman, her kata etkiyen 7 yanal yük, 35 adet düşey yayılı yük bulunmaktadır. İskele 6 adet sabit mesnetle desteklenip iç akslarda yer alan 4 mesnette oturma olmaktadır. İş iskelesi açı yöntemi ile analiz edilecek olsaydı 53x53 boyutundaki matris tersinin hesaplanması gerekecekti. Bunun dışında klasik moment dağıtma yöntemi ile çözümde ise 12 kere moment dağıtma yönteminin uygulanması ve elde edilen denklem kümesinin çözümü için $11 \times 11$ boyutundaki matris tersinin hesaplanması gerekmektedir. Buna ek olarak elde edilen 12 çözümün bellekte saklanması gerekmektedir. İyileştirilmiş MDY 22 yineleme sonucunda 16146 adet çarpma yaparak esas çözüme yakınsamıştır. Başlangıç değerine göre düzeltmeler \%0,0001 mertebesine kadar küçülmüştür.

İş iskelesinin sonlu elemanlar yöntemi ile analizi durumunda 144x144 boyutunda matris tersinin hesaplanması gerekecektir. Açı ve sonlu eleman yöntemleri tarafindan oluşturulan katsayı matrisleri seyrek matristir. Seyrek matrislerin nümerik çözümü göreceli olarak daha kolay olmakla birlikte çözüm için gereken tekrar sayısı ve hesap yükü matris boyutuna oranla üstel biçimde artmaktadır [5]. Gauss Yöntemi ile doğrusal denklem sisteminin çözümü $\mathrm{O}\left(\mathrm{n}^{3}\right)$ aritmetik karmaşıklığa sahiptir. Bu durumda sonlu elemanlar yöntemi açı yöntemine göre yaklaşı 20 kat daha fazla hesap yükü getirmektedir. Buna ek olarak katsayıların bellekte tutulması için Açı Yöntemine göre yaklaşık 9 kat daha fazla belleğe ihtiyaç duyulmaktadır. Bellek ve işlemci gücü ihtiyacı masaüstü ve dizüstü bilgisayarlar için ihmal edilebilir olmakla birlikte elde taşınabilir cihazlar için önemlidir.

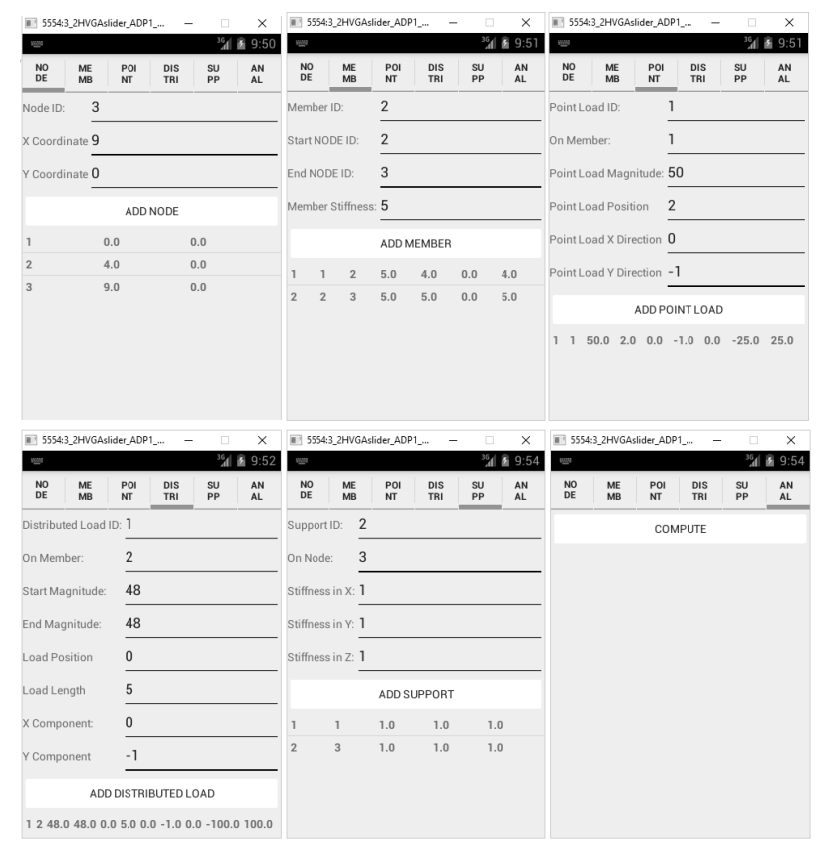

Şekil 3. Android uygulamasının veri giriş ekran çıtktları 
İyileştirilmiş MDY matris tersi hesaplanmasına gerek duymamasının yanı sıra değişkenlerin matris biçiminde saklanma zorunluluğu olmadığı için önemli ölçüde bellek tasarrufu da sağlamaktadır. Son örnek problemde dügüm noktaları, yükler, mesnetler ve elemanların tanımlanması için $3 \mathrm{kB}$, eleman ve düğüm noktalarının topolojisi ve değişkenler için $5 \mathrm{kB}$ bellek kullanılmıştır. Android işletim sisteminde çalışması için derlenen dosya $167 \mathrm{kB}$ boyutunda olup geliştirilen yöntemin hesap yükü, bellek ve sığa gereksinimi oldukça makul düzeydedir. Android işletim sistemine sahip akıllı telefonlar için geliştirilen uygulamanın ekran görüntüleri Şekil 3'te sunulmuştur. Elde edilen ekran görüntüleri 3,2 inç ekran genişliğinde alınmıştır.

\section{IYYILEŞTIRILILMIŞS MDY'NIN YAKINSAMA ANALIZİ}

Açı Yöntemi her zaman diyagonalde baskın katsayılar matrisi oluşturur. Bu nedenle mevcut moment dağıtma yönteminin Jacobi tekrarlı yöntemi ile çözümünün yakınsaması kesindir [6]. Yapıda yanal deplasman ve oturma görülmesi yakınsamayı etkilememektedir. Çünkü bu etkiler ayrı ayrı ele alınmakta ve katsayı matrisine dâhil edilmemektedir. Ancak düğüm noktaları ile eleman rotasyonlarının birlikte çözülmesiyle bahsi geçen parametreler katsayılar matrisine dâhil edilmektedir. Bunun sonucunda katsayılar matrisi değişmekte ve Jacobi tekrarının yakınsama kesinliğinin incelenmesi gerekmektedir. Jacobi yakınsaması $A x=b$ denklem kümesi için eşitlik 4 'te gösterilmiştir.

$x^{(m+1)}=b+(I-A) x^{(m)}$

Eşitlikte; $x^{(m+1)} m+1$ inci yakınsama sonundaki değişkenlerin değerlerini, $x^{(m)}, m$ inci yakınsama sonunda elde edilen değişkenlerin değerlerini, $I$ birim matrisi ve $A$ katsayılar matrisini ifade eder. Katsayılar matrisinin spektral yarıçapının mutlak değeri l'den küçük olduğu durumda değişkenler için atanan herhangi $x^{0}$ başlangıç durumunda tekrarlı çözümün yakınsaması kesindir [7]. Spektral yarıçapı, katsayılar matrisinin öz (eigen) değerlerinden en büyük mutlak değere sahip olanına eşittir. Spektral yarıçapı hesaplamak için katsayılar matrisi, $A$,nın $j^{\prime}$ ninci satırı $a_{j j}$ elemanına bölünerek normalleştirilir. İlk iki örnek problemde incelenen yapıların spektral yarıçapları ile yanal deplasman ve oturmanın olmadığı yapının spektral yarıçapı karşılaş̧ırılmıştır. Birinci problemin öz değerleri $(-0,3750,0,3750)$, İkinci problemin öz değerleri $(0,6594,-0,3750,-0,2844)$ olarak hesaplanmıştır. Oturma görülen temel için yatak katsayısı, $k, \lambda E K$ ile değiştirilmiştir. Yanal deplasman parametrelerinin eklenmesi spektral yarıçap değerini arttırmasına rağmen yakınsama kesindir.

Spektral yarıçap değeri yay katsayısına bağlı olduğu için bu durum özel olarak incelenmiştir. Yatak katsayısı için çok düşük ve çok yüksek değerler atanarak bu parametrenin yakınsama üzerindeki etkisi incelenmiştir. Yatak katsayısına sıfırdan başlayarak sonsuza kadar farklı aralıklarda değerler atanıp katsayı matrisinin öz değerleri hesaplanmıştır. Temel sertliği arttıkça öz değerlerinin mutlak değerleri azalmaktadır (Çizelge 1). Çizelgenin altıncı kolonunda yakınsama oranı sunulmuştur.

Moment dağıtma yönteminde başlangıç değeri olarak sistemdeki tüm düğüm noktalarının dönüklüğ̈̈ sıfır alınmaktadır. Fakat yakınsamayı deneysel test etmek için farklı yay katsayıları ve farklı başlangıç değerleri ile çerçeve yapı tekrar çözülmüş ve yakınsanan sonucun başlangıç değerinden bağımsız olduğu bulunmuştur. Temel yay katsayısının sıfır 
olması düşey mesnet tepkisinin her zaman sıfır olmasını gerektirir. Bu durumda esas çözüm olan 0 değerine yakınsamakta ancak hesap yükü makul değerlerin çok üzerinde olmaktadır. Yakınsama durumunun incelenmesi yatak katsayısına negatif değerler atanarak, $\lambda<0$, tekrar edilmiştir. Negatif yatak katsayısı gerçek dışı ve fiziksel olarak anlamsız olmasına karşın sadece yakınsama üzerindeki etkisini gözlemleme amacıyla atanmıştır. Elde edilen öz değerleri ve yakınsama oranı Çizelge 2 'de verilmiştir.

Çizelge 1. Küçük çerçeve için temel pabuç sertliğinin yakınsamaya etkisi

\begin{tabular}{|c|c|c|c|c|c|}
\hline$\lambda(\mathbf{E K})$ & Öz 1 & Öz 2 & Öz 3 & Öz 4 & Yakın. Oran \\
\hline 0 & 1,3484 & $-0,9734$ & $-0,3750$ & 0,000 & 1,05302 \\
\hline 1 & 1,1883 & $-0,8133$ & $-0,3750$ & 0,000 & 1,52839 \\
\hline 2,25 & 1,0736 & $-0,6986$ & $-0,3750$ & 0,000 & 2,18023 \\
\hline 5 & 0,9437 & $-0,5687$ & $-0,3750$ & 0,000 & 4,46915 \\
\hline 10 & 0,8427 & $-0,4677$ & $-0,3750$ & 0,000 & 5,09628 \\
\hline 50 & 0,7082 & $-0,3750$ & $-0,3332$ & 0,000 & 5,39809 \\
\hline 250 & 0,6699 & $-0,3750$ & $-0,2949$ & 0,000 & 6,02289 \\
\hline$\infty$ & 0,6594 & $-0,3750$ & $-0,2844$ & 0,000 & 6,24630 \\
\hline
\end{tabular}

Çizelge 2. Negatif yatak katsayısının yakınsamaya etkisi

\begin{tabular}{|c|c|c|c|c|c|}
\hline$\lambda(\mathbf{E K})$ & Öz 1 & Öz 2 & Öz 3 & Öz 4 & $\begin{array}{c}\text { Yakınsama } \\
\text { Oranı }\end{array}$ \\
\hline 0,00 & 1,348 & $-0,973$ & $-0,375$ & 0,000 & 1,053 \\
\hline$-0,05$ & 1,359 & $-0,984$ & $-0,375$ & 0,000 & 1,030 \\
\hline$-0,10$ & 1,371 & $-0,996$ & $-0,375$ & 0,000 & 1,007 \\
\hline$-0,11$ & 1,373 & $-0,998$ & $-0,375$ & 0,000 & 1,002 \\
\hline$-0,12$ & 1,375 & $-1,000$ & $-0,375$ & 0,000 & 0,997 \\
\hline$-0,15$ & 1,382 & $-1,007$ & $-0,375$ & 0,000 & 0,983 \\
\hline
\end{tabular}

Yakınsama $\lambda>-1,12$ koşulu sağlandığı sürece gerçekleşmekte ancak $\lambda \leq-1,12$ durumunda yakınsama oranının 1'den küçük olduğu yanı denklemlerin ıraksadığı görülmektedir. Aynı şekilde öz değerleri incelendiğinde de $\lambda \leq-1,12$ koşulu gerçekleştiğinde mutlak değeri en büyük ikinci öz değerinin de mutlak değerinin 1 den büyük duruma geldiği görülmektedir. Deneysel inceleme sonucunda öz değerlerinden sadece birinin mutlak değerinin 1'den büyük olması durumunda yakınsamanın ani yavaşladığı, ikisinin mutlak değerinin 1'den büyük olması durumunda ise ıraksamanın olduğu tespit edilmiştir.

Temel yatak katsayısının negatif olması mesnet zemine gömüldükçe üzerindeki kolonu daha büyük kuvvetle aşağı yönde çektiği anlamına gelmektedir. Bu durumda yapının 
stabilitesi $\mathrm{B}$ ve $\mathrm{C}$ düğüm noktalarının yapının dönmeye gösterdiği dirençle sağlanmaktadır. $\mathrm{BC}$ kirişinin rotasyonu için gereken çekme kuvveti temelde oluşan çekme kuvvetinden fazla olduğu sürece yapı dengede kalmaktadır. Bu denge durumu ancak $\lambda \leq-1,12$ koşulu oluştuğunda bozulmakta ve $\mathrm{B}$ düğüm noktasının rijitliği yeterli gelmeyip $\mathrm{D}$ düğüm noktası sürekli aşağı yönlü hareket etmektedir. Yakınsamanın olmadığı durumda yapı da stabil değildir. Bir başka değişle analiz edilen yapı stabil oldukça yakınsama kesindir.

\section{SONUÇ}

Bu çalışmada moment dağıtma yöntemi iyileştirilerek düğüm ve eleman rotasyonlarının beraber çözülebilmesini sağlamıştır. Bu sayede oturma ve yanal deplasmana maruz çerçeve yapıların analizi için moment dağıtma yöntemini çok sayıda tekrarlama zorunluluğu ortadan kalkmıştır. Böylece oturmaya ve yanal deplasmana maruz çok katlı yapıların moment dağıtma yöntemi ile analizi daha az hesap yükü gerektirir hale gelmiş ve yöntemin programlanması kolaylaşmıștır. Suni kısıtlamaların uygulanma gerekliliğinin ortadan kalkması algoritmanın kolaylaşmasının yanı sıra bellek ihtiyacını da önemli ölçüde düşürmüştür. Yapılan yakınsama analizi sonucunda yöntemin stabil yapılar için yakınsamasının kesin olduğu tespit edilmiştir. Böylece çerçeve yapıların analizinin elde taşınır cihazlar olan programlanabilir hesap makinesi ve akıllı telefonlarda yapılabilmesi sağlanmıştır.

Yakınsama üzerine yapılan duyarlılık analizi doğrusal sistemlerin yakınsaması üzerine önemli bulgular sağlamıştır. Katsayılar matrisinin öz değerlerinden sadece birinin 1'den büyük olması durumunda yakınsamanın önemli ölçüde yavaşladığı tespit edilmiştir. Ayrıca öz değerlerinden ikisinin mutlak değerinin 1'den büyük olması durumunda denklemlerin ıraksadığı belirlenmiştir. Öz değerlerinden birinin mutlak değerinin 1'den büyük olma durumu çerçeve yapılarda yaygın olarak görülmektedir ancak yapı stabil oldukça öz değerlerinin mutlak değeri en büyük olan ikincisinin mutlak değerinin her zaman 1'den küçük olacağı deneysel olarak gösterilmiştir.

Geliştirilen algoritmanın elde taşınabilen cihazlarda çalıștırılması ile saha mühendisleri şantiyedeki çalışmasını kesmeden öngörülemeyen yük kombinasyonlarını anında analiz etme imkânına sahip olacaktır. Bu sayede saha mühendisleri inşaat işinin durmasına sebep olmamak için sezgisel kararlar almak zorunda kalmayacaklardır. Saha mühendisleri analizleri gerçek zamanlı yapabilme olanağına kavuşması sayesinde merkez ofise daha az danışacak ve şantiye ofisi ile merkez ofis arasındaki veri akışı ihtiyacı önemli ölçüde azalacaktır. Bu sayede şantiye personeli daha fazla esnekliğe sahip olabilecek ve kendi kararlarını daha kısa sürede alabileceklerdir. Bunun sonucunda inşaat işi daha hızlı ilerleyecek ve yazışmaların azaltılması ve yapım süresince oluşan duraklamaların azalması sonucunda dolaylı maliyetlerde önemli ölçüde azalma sağlanabilecektir.

Yapı analizinin elde taşınır cihazlarla yapılabilmesi özellikle şantiyede tespit edilen şüpheli durumların gerçek zamanlı incelenip karar verilmesini sağlaması bakımından oldukça yararlıdır. Bu sayede saha mühendisleri sezgisel karar almayıp analiz sonuçlarına göre karar vereceği için daha güvenli şantiye yönetiminin temin edilmesi sağlanacaktır. Ayrıca saha mühendisleri daha güvenli biçimde karar alabileceği için şantiye ofisi ile merkez ofisi arasındaki bilgi alış verişi önemli ölçüde azalacak ve yapım işi daha hızlı ilerleyecektir. 


\section{Teşekkür}

Bu çalışma TÜBİTAK'ın 1059B191400951 numaralı desteği ile yürütülmüştür.

\section{Kaynaklar}

[1] West H.H. ve Geshwindner L.F., "Fundamentals of Structural Analysis", John Wiley \& Sons, United States of America, 2002.

[2] Leet K. ve Uang C.M., "Fundamentals of Structural Analysis (second ed)", McGrawHill Education, 2002.

[3] Maney G.A., "Studies in Engineering", Minneapolis: University of Minnesota, 1915.

[4] Cross H., "Analysis of Continuous Frames by Distributing Fixed-End Moments", Proceedings of the American Society of Civil Engineers (ASCE) 919-928, 1930.

[5] Golub G.H., Van L. ve Charles F., "Matrix Computations (third ed.)", Baltimore: Johns Hopkins, 1996.

[6] Volokh K.Y. "On foundations of the Hardy Cross method", International Journal of Solids and Structures 39(16), 4197-4200, 2002.

[7] Kreyszig E., "Advanced Engineering Mathematics (Eight Ed.)", John Wiley \& Sons, Singapore, 1999. 